\title{
1D-Zigzag $\mathrm{Eu}^{3+} / \mathrm{Tb}^{3+}$ Coordination Chains as Luminescent Ratiometric Thermometers Endowed with Multicolor Emission
}

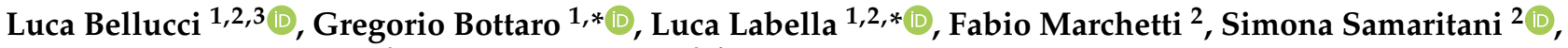 \\ Daniela Belli Dell'Amico ${ }^{2}$ and Lidia Armelao ${ }^{3,4}$
}

1 Istituto di Chimica della Materia Condensata e di Tecnologie per l'Energia, Consiglio Nazionale delle Ricerche, ICMATE-CNR and INSTM, Dipartimento di Scienze Chimiche, Università di Padova, via Marzolo 1, I-35131 Padova, Italy; luca.bellucci@phd.unipd.it

2 Dipartimento di Chimica e Chimica Industriale and CIRCC, Università di Pisa, via Giuseppe Moruzzi 13, I-56124 Pisa, Italy; fabio.marchetti@unipi.it (F.M.); simona.samaritani@unipi.it (S.S.); daniela.belli@unipi.it (D.B.D.)

3 Dipartimento di Scienze Chimiche and INSTM, Università di Padova, via Marzolo 1, I-35131 Padova, Italy; lidia.armelao@unipd.it

4 Dipartimento di Scienze Chimiche e Tecnologie dei Materiali (DSCTM), Consiglio Nazionale delle Ricerche, Piazzale A. Moro 7, 00185 Rome, Italy

* Correspondence: gregorio.bottaro@cnr.it (G.B.); luca.labella@unipi.it (L.L.); Tel.: +39-049-8275275 (G.B.); +39-050-2219262 (L.L.)

check for updates

Citation: Bellucci, L.; Bottaro, G.; Labella, L.; Marchetti, F.; Samaritani, S.; Belli Dell'Amico, D.; Armelao, L. 1D-Zigzag $\mathrm{Eu}^{3+} / \mathrm{Tb}^{3+}$ Coordination Chains as Luminescent Ratiometric Thermometers Endowed with Multicolor Emission. Materials 2021, 14, 6445. https://doi.org/10.3390/ ma14216445

Academic Editor: Halina Kaczmarek

Received: 1 October 2021

Accepted: 23 October 2021

Published: 27 October 2021

Publisher's Note: MDPI stays neutral with regard to jurisdictional claims in published maps and institutional affiliations.

Copyright: (c) 2021 by the authors. Licensee MDPI, Basel, Switzerland. This article is an open access article distributed under the terms and conditions of the Creative Commons Attribution (CC BY) license (https:// creativecommons.org/licenses/by/ $4.0 /)$.
Abstract: Two homometallic Coordination Polymers (CPs) with composition [ $\operatorname{Ln}(\mathrm{hfac})_{3}$ bipy $]_{\mathrm{n}}\left(\mathrm{Ln}^{3+}\right.$ $=\mathrm{Eu}^{3+}, \mathbf{1}$, and $\mathrm{Tb}^{3+}, 2$; hfac $=$ hexafluoroacetylacetonato, bipy $=4,4^{\prime}$-bipyridine) were used to develop a family of ratiometric luminescent thermometers containing $\mathrm{Eu}^{3+}$ and $\mathrm{Tb}^{3+}$ as red and green emitters, respectively. The thermometric properties of pure CPs and of their mixtures having an $\mathrm{Eu}^{3+} / \mathrm{Tb}^{3+}$ molar ratio of 1:1, 1:3, 1:5, and 1:10 (samples: Eu1Tb1, Eu1Tb3, Eu1Tb5, and Eu1Tb10) were studied in the 83-383 $\mathrm{K}$ temperature range. Irrespective of the chemical composition, we observed similar thermometric responses characterized by broad applicative temperature ranges (from 100 to $165 \mathrm{~K}$ wide), and high relative thermal sensitivity values $\left(\mathrm{S}_{\mathrm{r}}\right)$, up to $2.40 \% \mathrm{~K}^{-1}$, in the physiological temperature range (298-318 K). All samples showed emissions endowed with peculiar and continuous color variation from green $(83 \mathrm{~K})$ to red $(383 \mathrm{~K})$ that can be exploited to develop a colorimetric temperature indicator. At fixed temperature, the color of the emitted light can be tuned by varying composition and excitation wavelength.

Keywords: luminescence; europium; terbium; lanthanide coordination polymers; luminescent molecular thermometers; ratiometric thermometers

\section{Introduction}

Nowadays, luminescence thermometry plays a relevant role due to its high importance in many societal needs. For example, contactless temperature measurements with a sub-micrometric spatial resolution are required in countless technological applications and industrial fields, such as microelectronics, microoptics, photonics, microfluidics, and nanomedicine (e.g., in intracellular temperature measurements, or in microcircuit thermal map) [1-3]. Among the different types of luminescent thermometers, intensity-based ones are particularly useful for many applications such as real-time measurements on large moving systems $[4,5]$. However, using a single emitter, fluctuations of the light source or changes in the emitter local concentration are potential sources of error in temperature readout [6-8].

The stated drawbacks can be easily overcome using the intensity ratio of different emission bands of a given luminescent material, thus creating self-referencing thermometers $[6,7,9,10]$. These thermometers, also called "ratiometric thermometers", have been developed using a variety of luminescent probes $[7,8,11]$. Among others, europium and 
terbium complexes have been extensively used due to their peculiar luminescent properties $[6,12-17]$.

Lanthanide Metal-Organic Frameworks (MOFs) and Coordination Polymers (CPs) immediately appeared to be excellent platforms for the development of ratiometric thermometers $[3,11,15,17,18]$. Indeed, the possibility to introduce different metal ions simultaneously in MOFs and CPs, without altering their structure, marked them as two of the most promising materials for the development of luminescent thermometers. Furthermore, the rational fine tuning of their luminescent properties simply varying the nature of the different building blocks (e.g., metal ions, spacer ligands, and guest molecules) or their sequence within the network, i.e., the so-called "spatial composition" $[19,20]$, give countless possibilities for the creation of systems with desired properties [11,21,22]. Nevertheless, dual metal center thermometers allow to associate temperature to the color of emitted light, making them particularly appealing for the development of colorimetric temperature sensors [23,24].

Polycarboxylates ligands have been extensively used for the development of luminescent thermometers based on $\mathrm{Eu}^{3+} / \mathrm{Tb}^{3+} \mathrm{MOFs}$ and $\mathrm{CPs}[3,11,13,17,25,26]$ due to the possibility of choosing from a wide variety of commercial/easily synthesized divergent ligands whose photoluminescent properties were suitable for the design of luminescent compounds. Conversely, examples of lanthanides MOFs and CPs endowed with thermometric properties and based on $\beta$-diketonate ( $\beta$-dike) ligands are relatively scarce in the literature $[27,28]$, though $\beta$-dike ligands have been widely employed in the synthesis of low-nuclearity lanthanide luminescent complexes with thermometric properties [9,29-32].

Recently, we developed a convenient strategy for the synthesis of a series of highly luminescent one-dimensional lanthanide zigzag polymeric chains with composition $[\operatorname{Ln}(\beta-$ dike $)_{3}$ (bipy) $]_{\mathrm{n}}$ based on lanthanide tris- $\beta$-diketonato complexes as nodes (for $\mathrm{Ln}^{3+}=\mathrm{Eu}^{3+}$ and $\mathrm{Tb}^{3+} ; \beta$-dike $=$ dibenzoylmethide, $\mathrm{dbm}$; while for $\mathrm{Ln}^{3+}=\mathrm{Eu}^{3+} \beta$-dike $=$ thenoyltrifluoroacetonate, tta, or hexafluoroacetilacetonate, $\mathrm{hfac}$ ) and 4,4'-bipyridine (bipy) as neutral spacer $[33,34]$. To develop a heterometallic ratiometric thermometer, the "antenna

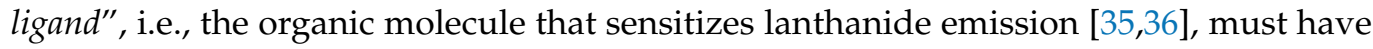
a triplet energy level high enough to promote the indirect excitation of both lanthanides ions. According to this requirement, the $\beta$-diketonate ligand hexafluoroacetylacetonate is a good choice for the development of europium and terbium-based ratiometric luminescent thermometers, since its excited triplet state $\left(T \approx 21,900 \mathrm{~cm}^{-1}\right)$ [37] has energy higher than europium ${ }^{5} \mathrm{D}_{0}\left(\approx 17,200 \mathrm{~cm}^{-1}\right)$ [38] and terbium ${ }^{5} \mathrm{D}_{4}\left(\approx 20,500 \mathrm{~cm}^{-1}\right)$ [31] emissive levels.

In this work, we studied a family of self-calibrating ratiometric thermometers, consisting of $\left[\mathrm{Eu}(\mathrm{hfac})_{3}(\text { bipy })\right]_{\mathrm{n}}$ and $\left[\mathrm{Tb}(\mathrm{hfac})_{3} \text { (bipy) }\right]_{\mathrm{n}}$ homometallic CPs and their mixture in a $\mathrm{KBr}$ matrix, endowed with temperature- and composition-dependent emission intensity and color between 83 and $383 \mathrm{~K}$. We preferred to mix the two homometallic CPs in an inert matrix over the direct synthesis of the corresponding heterobimetallic CPs to properly control spatial composition $[19,20]$ of the samples. In fact, due to the similar chemical properties $[39,40]$ of $\mathrm{Eu}^{3+}$ and $\mathrm{Tb}^{3+}$, the synthesis of heterobimetallic CPs will result in zigzag polymeric chains having random, statistically defined, $-\left(\mathrm{M}-\mathrm{M}^{\prime}\right)_{\mathrm{n}}-$ sequences $(-$ $=$ bridging ligand, $\mathrm{M}\left(\mathrm{M}^{\prime}\right)=\mathrm{Eu}^{3+}$ and $\left./ \mathrm{or}^{\mathrm{T}} b^{3+}\right)$.

Irrespective of the composition, the obtained materials are characterized by good thermometric properties in the $213-383 \mathrm{~K}$ temperature range. We highlighted how the color variation of the emitted light is exploitable to develop colorimetric thermometers even using the eyes as detector. This feature is of particular interest because it evidences the possibility for the spectroscopy-to-imaging readout transition for luminescence thermometers that would greatly increase their use and implementation into more complex tags, like QR-codes, easily readable with smartphones [24].

\section{Materials and Methods}

Anhydrous toluene was purchased from Merck and used without further purification. $\left[\mathrm{Eu}(\mathrm{hfac})_{3}\right]$ and $\left[\mathrm{Tb}(\mathrm{hfac})_{3}\right]$ were prepared from the corresponding bi-hydrated complex 
[Ln(hfac) $)_{3}\left(\mathrm{H}_{2} \mathrm{O}\right)_{2}$ ] according to the literature [33]. 4,4'-bipyridine (bipy, Aldrich) was used as received. All reactions have been carried out under inert Ar atmosphere using standard Schlenk techniques.

FTIR spectra in solid phase were recorded with a Perkin-Elmer "Spectrum One" spectrometer, equipped with an ATR accessory (Perkin Elmer, Waltham, MA USA). Elemental analyses $(\mathrm{C}, \mathrm{H}, \mathrm{N})$ were performed at the Dipartimento di Chimica e Chimica Industriale, Università di Pisa (Pisa, Italy). The metal content was determined by treating the samples with diluted $\mathrm{HNO}_{3}$ in a platinum crucible. The resulting solution was then evaporated to dryness. After calcination at $850{ }^{\circ} \mathrm{C}$, solid residues were weighted as $\mathrm{Eu}_{2} \mathrm{O}_{3}$ or $\mathrm{Tb}_{2} \mathrm{O}_{3}$.

Photoluminescence experiments have been performed on $\mathrm{KBr}$ pellets (Sigma-Aldrich, spectroscopic grade, Sigma-Aldrich, Burlington, MA, USA) containing pure CPs or their mixtures. $\mathrm{KBr}$ has been previously heated at $100{ }^{\circ} \mathrm{C}$ overnight to remove $\mathrm{H}_{2} \mathrm{O}$ traces. Room temperature luminescence spectra were recorded in a front-face acquisition geometry with a Horiba JobinYvon Fluorolog-3 spectrofluorimeter (Horiba JobinYvon, Edison, NJ, USA) equipped with double-grating monochromator in both the excitation and emission sides, coupled to a R928P Hamamatsu photomultiplier and a $450 \mathrm{~W}$ Xe arc lamp as the excitation source. Emission spectra were corrected for detection and optical spectral response of the spectrofluorimeter supplied by the manufacturer. The excitation spectra were corrected for the spectral distribution of the lamp intensity using a photodiode reference detector.

Temperature-dependent experiments (83-383 K) were carried out in backscattering geometry using a Horiba T64000 triple spectrometer equipped with a Peltier-cooled chargecoupled device detector (Horiba Synapse). A Xe arc lamp (450 W) has been used as excitation source. The scattered radiation was collected through a $10 \times$ microscope objective (Olympus MPLAN, $10 \times 0.25$, Olympus, Tokyo, Japan). The spectrograph, equipped with 300 lines/mm gratings, was used as a single-stage imaging monochromator. Temperaturedependent experiments were performed by means of a Linkam THMS600 heating/freezing microscope (Linkam, Tadworth, UK) stage having temperature stability $<0.1 \mathrm{~K}$ over the 83-873 K temperature range.

\subsection{Synthesis of $\left[\mathrm{Eu}(\mathrm{hfac})_{3}(\text { bipy })\right]_{n}(1)$}

[Eu(hfac) ${ }_{3}$ ] (0.603 g; $\left.0.78 \mathrm{mmol}\right)$ was suspended in toluene $(90 \mathrm{~mL})$, and 4,4'-bipyridine $(0.125 \mathrm{~g} ; 0.80 \mathrm{mmol})$ was added. After $2 \mathrm{~h}$ stirring at about $60^{\circ} \mathrm{C}$, the yellowish solution was slowly cooled to room temperature. The precipitated solid was filtered off and dried in vacuo at room temperature for four hours $\left(0.543 \mathrm{~g}\right.$ yield $75.0 \%$ as $\left[\mathrm{Eu}(\mathrm{hfac})_{3}(\right.$ bipy)] $)$. El. Anal. Calc. for [Eu(hfac) $)_{3}$ (bipy)], $\mathrm{C}_{25} \mathrm{H}_{11} \mathrm{EuF}_{18} \mathrm{O}_{6} \mathrm{~N}_{2}: \mathrm{C}, 32.3 ; \mathrm{H}, 1.2 ; \mathrm{Eu}, 16.4 ; \mathrm{N}$, 3.0. Found: C, 32.6; H, 1.3; Eu, 16.6; N, 2.8\%. ATR IR: (range: $\left.1700-700 \mathrm{~cm}^{-1}\right) 1647(\mathrm{~s}, v \mathrm{C}=\mathrm{O}), 1608(\mathrm{mw}$, $v \mathrm{C}=\mathrm{C}), 1558(\mathrm{mw}, v \mathrm{C}=\mathrm{O}+\delta \mathrm{C}-\mathrm{H}), 1534(\mathrm{~m}), 1461(\mathrm{~ms}), 1418(\mathrm{mw}), 1251(\mathrm{~s}), 1199(\mathrm{~s}), 1141(\mathrm{~s})$, 1101 (s, vC-F), 1069 (m), 1047 (mw), 1005 (mw), 972 (w), 951 (w), 858 (w), $800(\mathrm{~ms}), 767$ (w), $733(\mathrm{~m})$.

\subsection{Synthesis of $\left[T b(h f a c)_{3}(\text { bipy })\right]_{n}(2)$}

[Tb(hfac) $)_{3}$ ( $\left.0.998 \mathrm{~g} ; 1.28 \mathrm{mmol}\right)$ was suspended in toluene $(100 \mathrm{~mL})$ and $4,4^{\prime}$-bipyridine $(0.200 \mathrm{~g} ; 1.28 \mathrm{mmol})$ was added. The suspension was heated for $2 \mathrm{~h}$ at $60{ }^{\circ} \mathrm{C}$, obtaining a yellow solution which was slowly cooled to room temperature. A suspension of a microcrystalline solid was obtained, filtered, and dried in vacuo at room temperature for four hours (1.019 g yield $85.0 \%$ as [ $\mathrm{Tb}(\text { hfac) })_{3}$ (bipy)]). El. Anal. Calc. for [ $\mathrm{Tb}(\text { hfac })_{3}($ bipy) $]$, $\mathrm{C}_{25} \mathrm{H}_{11} \mathrm{TbF}_{18} \mathrm{O}_{6} \mathrm{~N}_{2}: \mathrm{C}, 32.1 ; \mathrm{H}, 1.2 ; \mathrm{N}, 3.0 ; \mathrm{Tb}, 17.0$. Found: $\mathrm{C}, 32.0 ; \mathrm{H}, 1.2 ; \mathrm{N}, 3.3 \% ; \mathrm{Tb}$, 17.8. ATR IR: (range: 1700-700 cm $\left.\mathrm{cm}^{-1}\right) 1647(\mathrm{~s}, v \mathrm{C}=\mathrm{O}), 1608(\mathrm{mw}, v \mathrm{C}=\mathrm{C}), 1558(\mathrm{mw}, v \mathrm{C}=\mathrm{O}+$

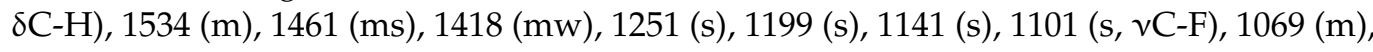
$1047(\mathrm{mw}), 1005(\mathrm{mw}), 972(\mathrm{w}), 951(\mathrm{w}), 858(\mathrm{w}), 800(\mathrm{~ms}), 767(\mathrm{w}), 733(\mathrm{~m})$.

\subsection{Preparation of $\mathrm{KBr}$ Pellets Containing $\left[\mathrm{Ln}(\mathrm{hfac})_{3}(\text { bipy })\right]_{n}\left(\mathrm{Ln}^{3+}=E u^{3+}, \mathrm{Tb}^{3+}\right) \mathrm{CPS}$}

Known amounts of $\left[\operatorname{Ln}(\mathrm{hfac})_{3}(\text { bipy })\right]_{\mathrm{n}}\left(\mathrm{Ln}^{3+}=\mathrm{Eu}^{3+}, \mathrm{Tb}^{3+}\right)$ were dispersed in the proper amount of dried $\mathrm{KBr}$ to obtain the desired europium/terbium molar ratio. The 
total lanthanide $\left(\mathrm{Eu}^{3+}+\mathrm{Tb}^{3+}\right)$ molar concentration was kept constant. The mixtures were grinded in an agate mortar, adding few drops of n-pentane, dried under a gentle $\mathrm{N}_{2}$ flow, and then pressed, forming the pellets. Six pellets were prepared, two containing the pure CPs (1 and 2) and four made of a mixture of the two homometallic CPs with a 1:1, 1:3, 1:5, or 1:10 $\mathrm{Eu}^{3+} / \mathrm{Tb}^{3+}$ molar ratio (Eu1Tb1, Eu1Tb3, Eu1Tb5, and Eu1Tb10). Materials composition is summarized in Table 1 . The reproducibility in samples preparation was investigated through photoluminescence experiments comparing the intensity ratio between $\mathrm{Eu}^{3+5} \mathrm{D}_{0} \rightarrow{ }^{7} \mathrm{~F}_{2}(614 \mathrm{~nm})$ and $\mathrm{Tb}^{3+5} \mathrm{D}_{4} \rightarrow{ }^{7} \mathrm{~F}_{5}(543 \mathrm{~nm})$ transitions $\left(\mathrm{I}_{\mathrm{Eu}} / \mathrm{I}_{\mathrm{Tb}}\right)$ on three different replicates of Eu1Tb3. An experimental error of $\pm 10 \%$ was found.

Table 1. $\left[\mathrm{Eu}(\mathrm{hfac})_{3}(\text { bipy })\right]_{\mathrm{n}}(\mathbf{1})$ and $\left[\mathrm{Tb}(\mathrm{hfac})_{3}(\text { bipy })\right]_{\mathrm{n}}$ (2) amounts dispersed in $\mathrm{KBr}$ in the different samples.

\begin{tabular}{|c|c|c|c|}
\hline Sample & $\begin{array}{c}{\left[\mathrm{Eu}(\mathrm{hfac})_{3}(\mathrm{bipy})\right]} \\
(\mathrm{mmol})\end{array}$ & $\underset{(\mathrm{mmol})}{\left[\mathrm{Tb}(\mathrm{hfac})_{3}(\mathrm{bipy})\right]_{\mathrm{n}}}$ & $\mathrm{KBr}$ (mmol) \\
\hline 1 & $1.49 \mathrm{mg}\left(1.60 \times 10^{-3}\right)$ & // & $151.5 \mathrm{mg}(1.27)$ \\
\hline 2 & // & $1.30 \mathrm{mg}\left(1.39 \times 10^{-3}\right)$ & $133.6 \mathrm{mg}(1.12)$ \\
\hline Eu1Tb1 & $1.05 \mathrm{mg}\left(1.13 \times 10^{-3}\right)$ & $1.04 \mathrm{mg}\left(1.12 \times 10^{-3}\right)$ & $209.6 \mathrm{mg}(1.76)$ \\
\hline Eu1:Tb3 & $0.55 \mathrm{mg}\left(0.59 \times 10^{-3}\right)$ & $1.65 \mathrm{mg}\left(1.77 \times 10^{-3}\right)$ & $222.8 \mathrm{mg}(1.87)$ \\
\hline Eu1:Tb5 & $0.59 \mathrm{mg}\left(0.64 \times 10^{-3}\right)$ & $2.99 \mathrm{mg}\left(3.20 \times 10^{-3}\right)$ & $362.1 \mathrm{mg}(3.04)$ \\
\hline Eu1:Tb10 & $0.28 \mathrm{mg}\left(0.31 \times 10^{-3}\right)$ & $2.90 \mathrm{mg}\left(3.10 \times 10^{-3}\right)$ & $325.3 \mathrm{mg}(2.73)$ \\
\hline
\end{tabular}

\section{Results and Discussion}

\subsection{Synthesis and Characterization}

In our previous work, we carefully described the synthesis of monodimensional lanthanide $\beta$-diketonate coordination polymers based on bipy as connector ligand [33]. The synthesis of these CPs must be carried out in anhydrous toluene, avoiding the use of oxygenated solvents. Indeed, the presence of $\mathrm{O}$-donor molecules in the reaction environment led to the formation of low-nuclearity products due to the higher affinity of lanthanide ions towards oxygenated ligands than to $\mathrm{N}$-donor ones [41-43]. We also showed that $1 \mathrm{D}$ zigzag $\mathrm{CPs}$ were obtained regardless of the employed $\left[\operatorname{Ln}(\beta \text {-dike })_{3}\right]$ precursors, using an equimolar amount of bipy per metal center [33]. We also reported the synthesis and the characterization of $\left[\mathrm{Eu}(\mathrm{hfac})_{3}(\mathrm{bipy})\right]_{\mathrm{n}}(\mathbf{1})$. Its structure consists of $1 \mathrm{D}$ zigzag chains extended along the $b$ crystallographic axis (Figure 1). Each europium center is coordinated to six oxygen atoms from the three hfac ligands and two $\mathrm{N}$ atoms of two different bipy in a distorted square antiprismatic geometry [33].

a)

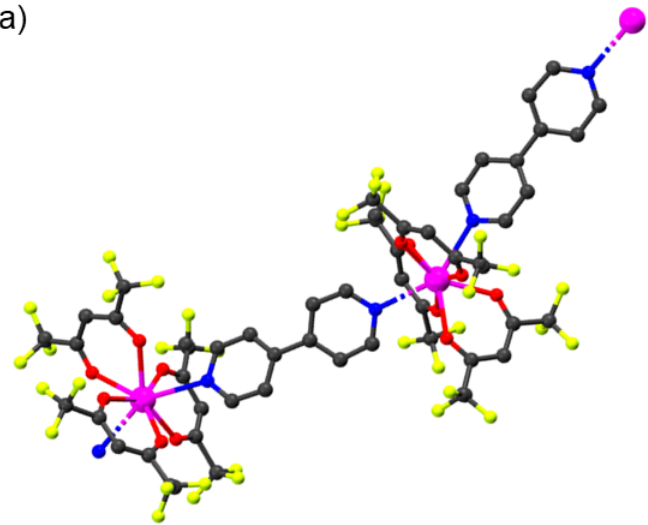

b)

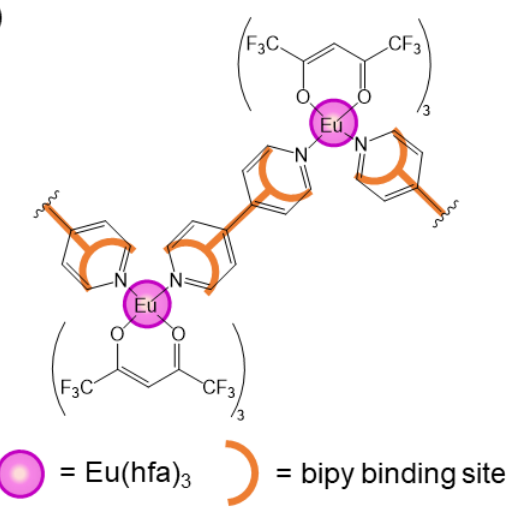

Figure 1. (a) Structure of a portion of the chain of $\left[\mathrm{Eu}(\mathrm{hfac})_{3}(\mathrm{bipy}) \cdot \text { toluene }\right]_{\mathrm{n}}$. Toluene molecules were omitted for clarity. CCDC number 1471967, from ref. [33]. (b) Schematic representation of $\left[\mathrm{Eu}(\mathrm{hfac})_{3}(\text { bipy) } \cdot \text { toluene }]_{\mathrm{n}}\right.$. 
The terbium $\mathrm{CP}\left[\mathrm{Tb}(\mathrm{hfac})_{3}(\text { bipy) }]_{\mathrm{n}}\right.$ (2) has been similarly synthesized, reacting $\left[\mathrm{Tb}(\mathrm{hfac})_{3}\right]$ and bipy in a 1:1 molar ratio, and characterized through elemental analysis and infrared spectroscopy (Figure S1).

\subsection{Photoluminescence and Thermometric Studies}

Upon irradiation, 1 and 2 emissions are excited over a wide wavelength range, from UV to visible, up to $\approx 450 \mathrm{~nm}$ for 1 and $\approx 400 \mathrm{~nm}$ for 2 (Figure S2). The lanthanidessensitized emission can be achieved through the so-called "antenna effect" exploiting the absorption properties of the organic ligands. The process can be summarized in the three following steps: (i) absorption of light by the organic ligand and population of its first excited singlet state $\left(\mathrm{S}_{1}\right)$; (ii) intersystem crossing (ISC) from the singlet to the triplet $\left(\mathrm{T}_{1}\right)$ level, and (iii) energy transfer (E.T.) from $\mathrm{T}_{1}$ to the lanthanide excited level [44]. Both the compounds showed intense light emission, also visible at the naked eye (Figure 2), red for $\mathbf{1}$ and green for 2 .
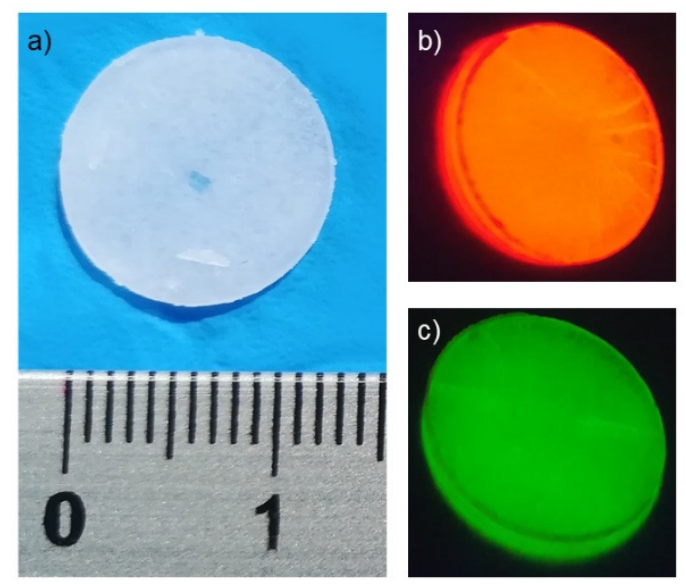

Figure 2. (a) Picture of a pellet illuminated with white light (the length scale is in $\mathrm{cm}$ ); and $(\mathbf{b}, \mathbf{c})$ picture of $\mathrm{KBr}$ pellets containing $\mathbf{1}(\mathbf{b})$ and 2 (c) exposed to UV light $\left(\lambda_{\mathrm{exc}}=320 \mathrm{~nm}\right)$ at room temperature.

In particular, the emission spectrum of 1 (Figure $3 a$ ) is characterized by the typical $\mathrm{Eu}^{3+5} \mathrm{D}_{0} \rightarrow{ }^{7} \mathrm{~F}_{\mathrm{J}}(\mathrm{J}=0-4)$ transitions corresponding to the bands centered at 587, 595, 614, 652, and $693 \mathrm{~nm}$. Conversely, compound 2 emission spectrum (Figure $3 \mathrm{~b}$ ) showed $\mathrm{Tb}^{3+5} \mathrm{D}_{4} \rightarrow{ }^{7} \mathrm{~F}_{\mathrm{J}}$ $(\mathrm{J}=6-3)$ transitions centered at $490,543,583$, and $619 \mathrm{~nm}$, respectively [45]. The spectra (Figure 3) of 1 and 2 , dominated by the ${ }^{5} \mathrm{D}_{0} \rightarrow{ }^{7} \mathrm{~F}_{2}\left(\mathrm{Eu}^{3+}\right)$ and ${ }^{5} \mathrm{D}_{4} \rightarrow{ }^{7} \mathrm{~F}_{5}\left(\mathrm{~Tb}^{3+}\right)$, have a shape that is typical for $\beta$-diketonato complexes [38,46].
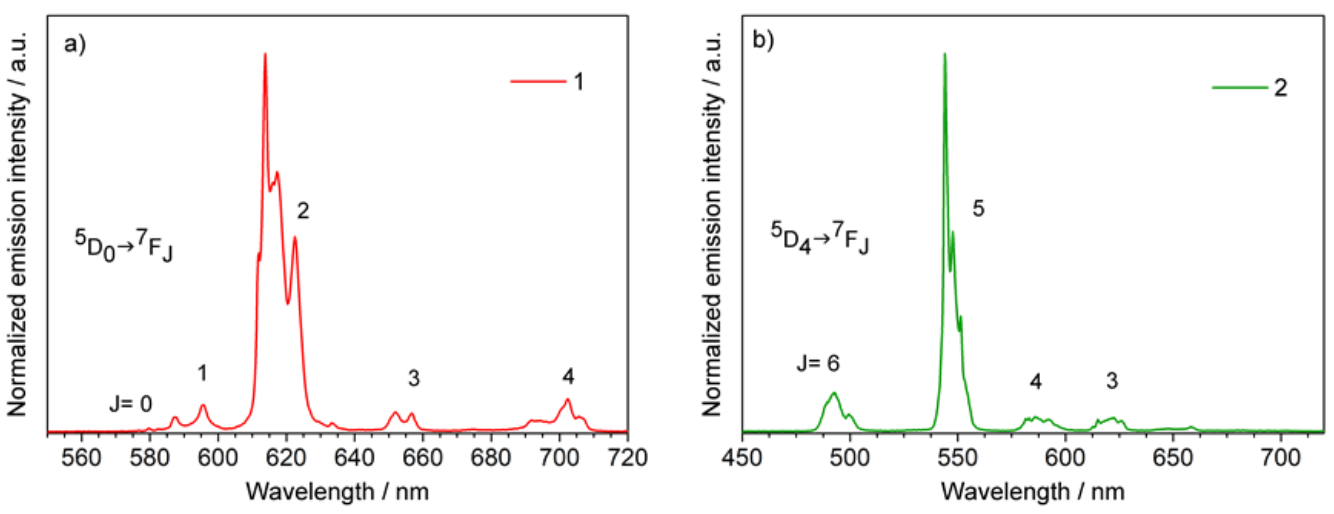

Figure 3. Emission spectra of compounds (a) 1 and (b) 2. $\lambda_{\text {exc }}=320 \mathrm{~nm}$.

The photoluminescence excitation (PLE, see Figure S2) spectrum of $\mathbf{2}$ is predominantly localized at $\lambda<380 \mathrm{~nm}$ with a low-intensity tail extending to the boundary with the visible 
region. Instead, the PLE spectrum of $\mathbf{1}$ is redshifted and extends in the visible up to about $450 \mathrm{~nm}$. Based on the shape of PLE spectra, we decided to study 1, 2 and their mixtures, exciting their luminescence at 320 and $370 \mathrm{~nm}$. While at $320 \mathrm{~nm}$ both emitters are effectively excited, PLE signals of $\mathbf{1}$ at $370 \mathrm{~nm}$ are more intense than for $\mathbf{2}$. However, the use of $370 \mathrm{~nm}$ excitation wavelength has distinctive applicative and technological advantages compared to $320 \mathrm{~nm}$, being compatible with organic substrates used in flexible electronics and with low glass transition temperature glasses having a cutoff wavelength around $350 \mathrm{~nm}$. Moreover, light-emitting devices (LEDs) emitting at $370 \mathrm{~nm}$ are quite common, and generally cheaper than UV LED.

The temperature-dependent luminescence properties of compounds $\mathbf{1}$ and $\mathbf{2}$ were studied in the 83-383 K temperature range. As visible from Figure 4c-e, the emission intensity of both compounds decreases as temperature increases. The integrated areas of $\mathrm{Eu}^{3+5} \mathrm{D}_{0} \rightarrow{ }^{7} \mathrm{~F}_{2}$ and $\mathrm{Tb}^{3+5} \mathrm{D}_{4} \rightarrow{ }^{7} \mathrm{~F}_{5}$ transitions were chosen as thermometric parameter $(\Delta)$ for $\mathbf{1}$ and 2, respectively, since they are the main contributions in the total emission spectra. The $\Delta$ curves of $\mathbf{1}$ and 2, normalized at $83 \mathrm{~K}$, are reported in Figure 4.
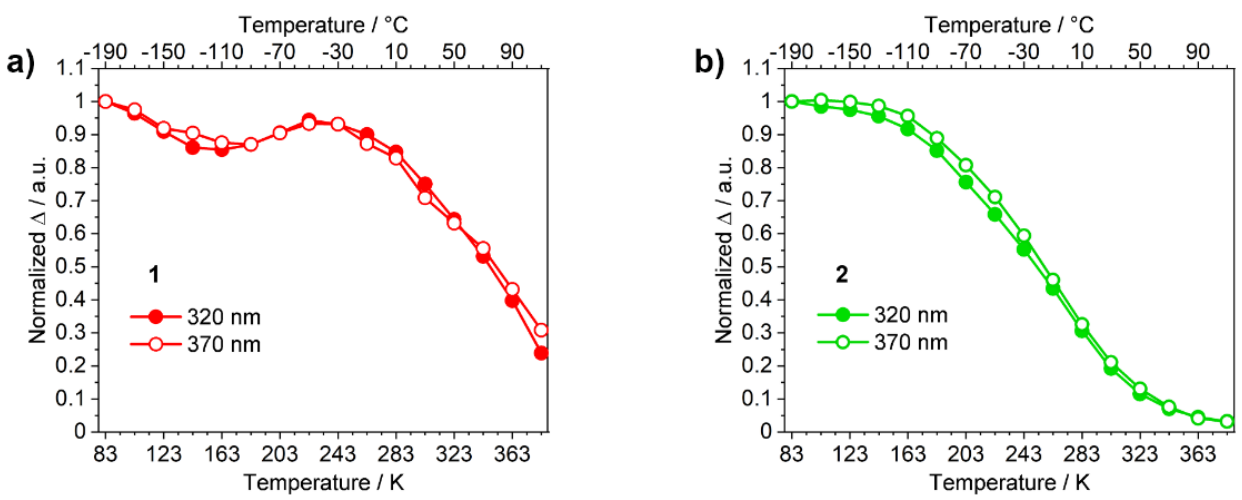

c) $\lambda_{\text {exc }}=320 \mathrm{~nm}$
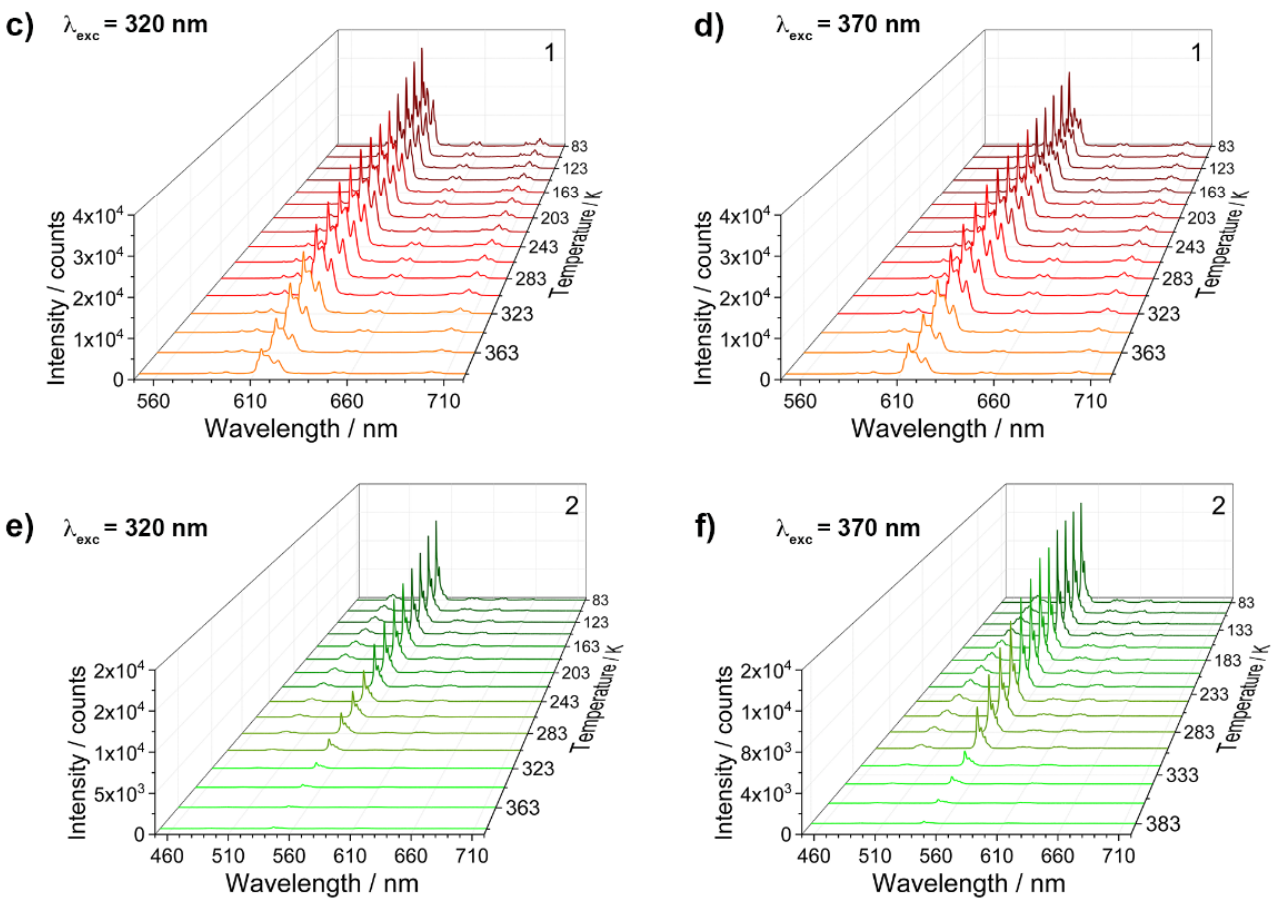

Figure 4. Comparison between the $\Delta$ curves of compounds (a) 1 and (b) 2. $\lambda_{\text {exc }}=320 \mathrm{~nm}(\bullet)$ and $370 \mathrm{~nm}(\mathrm{O})$. Emission spectra of $\mathbf{1}$ (c) $\lambda_{\text {exc }}=320 \mathrm{~nm},(\mathbf{d}) \lambda_{\text {exc }}=370 \mathrm{~nm}$, and $\mathbf{2}$ (e) $\lambda_{\text {exc }}=320 \mathrm{~nm},(\mathbf{f}) \lambda_{\text {exc }}=$ $370 \mathrm{~nm}$ 
The shape of $\Delta$ curves depends on the employed metal ion. In 1 (Figure 4a), the thermometric parameter has small variations up to $\approx 223 \mathrm{~K}$, and then decreases, keeping $25 \%$ ca. of the initial ${ }^{5} \mathrm{D}_{0} \rightarrow{ }^{7} \mathrm{~F}_{2}$ transition intensity at $383 \mathrm{~K}$ (Figure $4 \mathrm{c}, \mathrm{d}$ ). This trend does not depend on the employed excitation wavelength. Conversely, compound 2 showed a well-defined S-shaped profile that gradually decreases above $\approx 113 \mathrm{~K}$. Under the adopted experimental conditions, 2 did not show residual emission intensity at $383 \mathrm{~K}$ (Figure $4 \mathrm{~b}, \mathrm{e}, \mathrm{f}$ ). The emission of terbium- $\mathrm{CP}$ is partially quenched at room temperature, although still clearly observable, and gains intensity lowering the temperature. Europium emission is less effected and is very bright from physiological down to cryogenic temperatures ( $\mathrm{T}<100 \mathrm{~K}$ ) $[27,39]$. The shape of $\Delta$ vs. $\mathrm{T}$ curves depends on the balance between radiative and non-radiative deactivation pathways that contribute to the modulation of the luminescence properties. The most encountered non-radiative processes determining the overall thermometric response of the luminescent molecular thermometers are: (i) back energy transfer from $\mathrm{Ln}^{3+}$ to the ligand triplet level, (ii) multiphonon relaxation promoted by high energy oscillators (mainly $-\mathrm{OH}$ and $-\mathrm{NH}$ groups) directly bonded to the metal center, and (iii) energy transfer to LMCT states. Depending on the activation energies, more than one process can operate. Other deactivation paths can also be encountered but are less common (ion-ion interaction, donor-acceptor phenomena, etc.). The different behavior displayed by $\mathbf{1}$ and $\mathbf{2}$ is mainly correlated to the energy difference between $\mathrm{Eu}^{3+}$ or $\mathrm{Tb}^{3+}$ emitting levels and antenna triplet level (ca. 4700 and $1500 \mathrm{~cm}^{-1}$ for $\mathrm{Eu}^{3+}$ and $\mathrm{Tb}^{3+}$, respectively) that affect the efficiency of the energy transfer from $T_{1}$ to the lanthanide excited level, i.e., from the back energy transfer that results more efficient in 2. A contribution from LMCT states cannot be unambiguously ruled out [44].

For a better comparison of compounds $\mathbf{1}$ and $\mathbf{2}$ thermometric properties, we used the relative thermal sensitivity $\left(\mathrm{S}_{\mathrm{r}}, \% \mathrm{~K}^{-1}\right)[6]$, a figure of merit commonly adopted to compare thermometers was used:

$$
\mathrm{S}_{\mathrm{r}}=\frac{1}{\Delta}\left|\frac{\delta \Delta}{\delta \mathrm{T}}\right|
$$

In Equation (1), $\Delta$ is the thermometric parameter and $\delta \Delta$ is the variation of the thermometric parameter on a certain temperature variation ( $\delta \mathrm{T})$. A value of $\mathrm{S}_{\mathrm{r}} \geq 1$ was assumed as quality criterion to determine the applicative temperature range of these CPs [3].

Below $263 \mathrm{~K}$, compound 1 (Figure $5 \mathrm{a}$ ) has $\mathrm{S}_{\mathrm{r}}$ close to zero. Instead, $\mathrm{S}_{\mathrm{r}}$ is $>1$ above $323 \mathrm{~K}$ and its temperature-dependence is almost independent from the excitation wavelengths. Conversely, 2 (Figure $5 b$ ) has $S_{r} \neq 0$ in almost all the studied temperature range, with an application range from 243 to $383 \mathrm{~K}$.
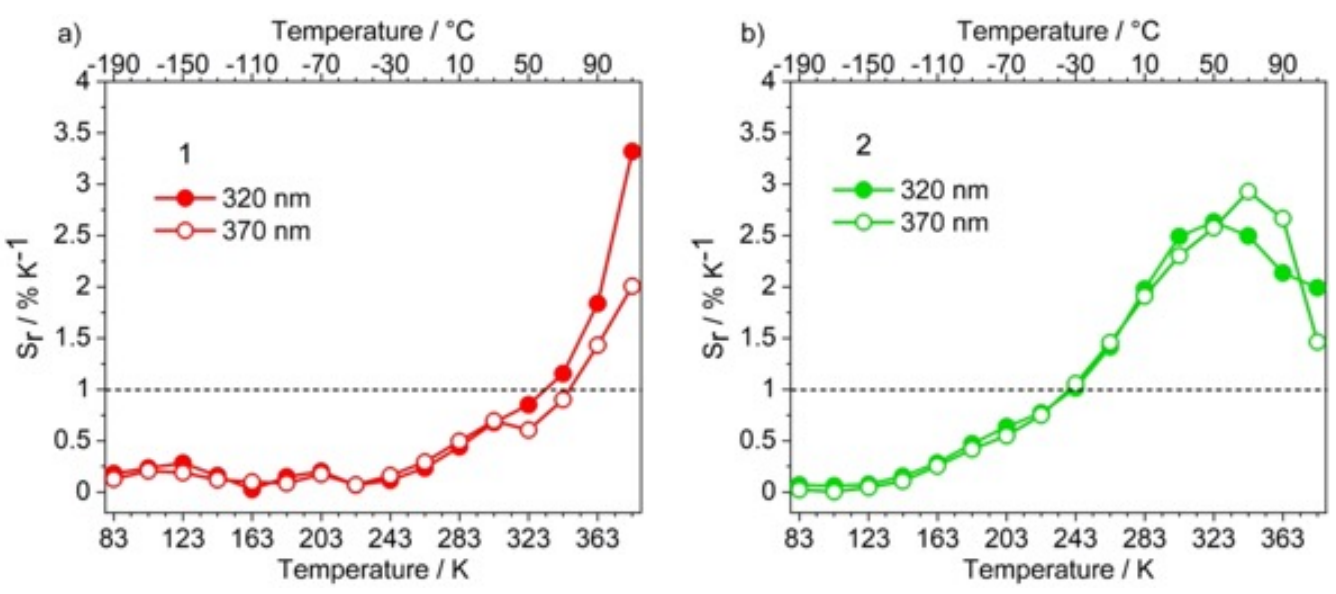

Figure 5. Comparison between the $S_{\mathrm{r}}$ curves of compounds (a) 1 and (b) $2 . \lambda_{\text {exc }}=320 \mathrm{~nm}(\bullet)$ and $370 \mathrm{~nm}(\bigcirc)$. 


\subsection{Development of $\mathrm{Eu}^{3+}-\mathrm{Tb}^{3+}$ Ratiometric Thermometers}

$\mathbf{1}$ and $\mathbf{2}$ are sensitive to temperature variation and can be efficiently employed to develop a family of ratiometric luminescent thermometers using the ${ }^{5} \mathrm{D}_{4} \rightarrow{ }^{7} \mathrm{~F}_{5}\left(\mathrm{~Tb}^{3+}\right) /{ }^{5} \mathrm{D}_{0} \rightarrow{ }^{7} \mathrm{~F}_{2}$ $\left(\mathrm{Eu}^{3+}\right)$ intensity ratio as thermometric parameter $\left(\Delta=\mathrm{I}_{\mathrm{Tb}} / \mathrm{I}_{\mathrm{Eu}}\right)$.

Known amounts of the two homometallic CPs (see Table 1) were mixed in $\mathrm{KBr}$, obtaining homogeneous dispersions. The mixtures have been finely grinded in an agate mortar, adding a few drops of n-pentane to facilitate the milling process. The organic solvent was then removed under $\mathrm{N}_{2}$ flow. Finally, the resulting powders have been pressed, forming non-friable easy-to-handle pellets. Four samples with different europium/terbium molar ratios have been prepared, keeping constant the $\mathrm{Ln}^{3+} / \mathrm{KBr}$ molar ratio $\left(\mathrm{Ln}^{3+}=\mathrm{Eu}^{3+}\right.$ $+\mathrm{Tb}^{3+}$ ). The samples were labelled Eu1Tb1, Eu1Tb3, Eu1Tb5, and Eu1Tb10 according to the $\mathrm{Eu}^{3+} / \mathrm{Tb}^{3+}$ relative amount (1:1, 1:3, 1:5, and 1:10 respectively).

At room temperature, the samples showed a bright homogeneous emission also visible to the naked eye. The color of the emitted light is a combination of the $\mathrm{Eu}^{3+}$ (red) and $\mathrm{Tb}^{3+}$ (green) emissions, which varies from orange to pale green, increasing the terbium content in the mixture (see Figure 6, Figure 7a,b, Figures S3 and S4).

Switching the excitation wavelength from $320 \mathrm{~nm}$ to $370 \mathrm{~nm}$, we modified the relative intensity of $\mathrm{Eu}^{3+}$ and $\mathrm{Tb}^{3+}$ emissions (compare Figure 7a,b, Figures S3 and S4), since the longer wavelengths favor europium emission with respect to the terbium one (see Figure S2). To check the sample homogeneity, we measured the emission spectra $\left(\lambda_{\text {exc }}=\right.$ $320 \mathrm{~nm}$ and $370 \mathrm{~nm}$ ) on different spots on each pellet (sampling size $=200 \mu \mathrm{m})$. We observed small differences in the $\mathrm{I}_{\mathrm{Tb}} / \mathrm{I}_{\mathrm{Eu}}$ intensity ratio, within $10 \%$, thus confirming a homogeneous dispersion of the two CPs inside the specimens.

The temperature-dependent luminescent properties of the mixed samples were studied in the 83-383 K range. As an example, emission spectra of Eu1Tb1 at $320 \mathrm{~nm}$ and $370 \mathrm{~nm}$ recorded at different temperatures are reported in Figure 7c,d (see also Figures S5 and S6 for the other samples).

Noteworthy, in all the samples the intensity of terbium ${ }^{5} \mathrm{D}_{4} \rightarrow{ }^{7} \mathrm{~F}_{5}$ transition is strongly influenced by temperature variations, while the europium ${ }^{5} \mathrm{D}_{0} \rightarrow{ }^{7} \mathrm{~F}_{2}$ band is less affected (Figure 7c,d, Figures S5 and S6), as also previously observed in the homometallic CPs $\mathbf{1}$ and 2. The color of the emitted light changes from green/yellow to orange/red depending on the sample composition and the excitation wavelength going from low to high temperature.

For all samples, $\Delta$ curves have a well-defined S-shape. Irrespective of the excitation wavelength, the higher the terbium content in the sample, the higher the $\Delta$ value at $83 \mathrm{~K}$ (Figure S7). To get qualitative information on the thermometric response among the mixed samples, the $\Delta$ curves were normalized at $83 \mathrm{~K}$ (Figure $8 \mathrm{a}, \mathrm{b}$ ).

In the mixed samples, the normalized $\Delta$ curves showed similar $\mathrm{S}$-shapes regardless of the relative europium/terbium amount and excitation wavelength. As a result, the $S_{r}$ vs. T curves, and hence the thermometric properties, of the different samples are quite similar (Figure $8 c, d$ ). All the $S_{r}$ curves showed an asymmetric bell shape with a $S_{r}$ maximum ( $\mathrm{S}_{\mathrm{rmax}}$ ) of $2.4 \% \mathrm{~K}^{-1} \mathrm{ca}$. between 303 and $323 \mathrm{~K}$ with an extended applicative temperature range ( $\mathrm{Sr} \geq 1,100 \mathrm{~K} \div 165 \mathrm{~K}$ wide), depending on the sample composition (see Table 2 ).

Table 2. Applicative temperature range $\left(S_{r} \geq 1\right)$ and $S_{r}$ maximum value $\left(S_{r m a x}\right)$ of the studied $\mathrm{Eu}^{3+} / \mathrm{Tb}^{3+}$ mixed samples.

\begin{tabular}{|c|c|c|c|c|}
\hline \multirow[b]{2}{*}{ Sample } & \multicolumn{2}{|l|}{$\lambda_{\mathrm{exc}}=320 \mathrm{~nm}$} & \multicolumn{2}{|l|}{$\lambda_{\mathrm{exc}}=370 \mathrm{~nm}$} \\
\hline & Applicative Temperature Range & $S_{r \max }(\mathrm{T})$ & Applicative Temperature Range & $S_{\text {rmax }}(T)$ \\
\hline Eu1Tb1 & $213-373 \mathrm{~K}$ & $2.20(303 \mathrm{~K})$ & $203-353 \mathrm{~K}$ & $2.30(303 \mathrm{~K})$ \\
\hline Eu1Tb3 & $223-363 \mathrm{~K}$ & $2.10(323 \mathrm{~K})$ & $243-343 \mathrm{~K}$ & $1.95(303 \mathrm{~K})$ \\
\hline Eu1Tb5 & $233-373 \mathrm{~K}$ & $2.10(303 \mathrm{~K})$ & $243-383 \mathrm{~K}$ & $1.95(323 \mathrm{~K})$ \\
\hline Eu1Tb10 & $233-373 \mathrm{~K}$ & $2.40(303 \mathrm{~K})$ & $233-363 \mathrm{~K}$ & $2.60(303 \mathrm{~K})$ \\
\hline
\end{tabular}

Interestingly, excellent $S_{r}$ values in the physiological temperature range (298-318 K) [27,47] were found for these ratiometric thermometers. 
The reproducibility of the thermometric response of the samples has been tested performing three different heating-cooling cycles on each sample. All the studied materials showed a highly reproducible thermometric response as well as the absence of thermal hysteresis (Figure 9).

\section{$\mathrm{UV}$ radiation $\left(\lambda_{\mathrm{exc}}=320 \mathrm{~nm}\right)$ at room temperature}

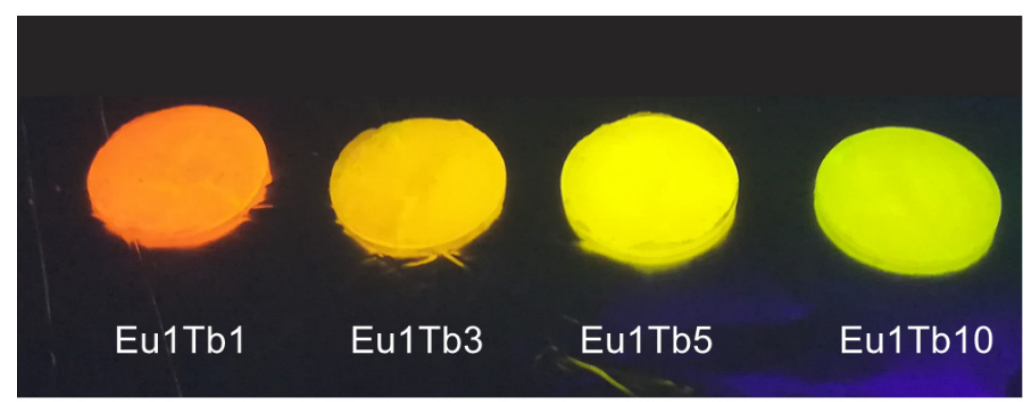

Figure 6. Room temperature $\mathrm{Eu}-\mathrm{Tb}$ mixed samples appearance under UV irradiation. $\lambda_{\mathrm{exc}}=320 \mathrm{~nm}$.

a)

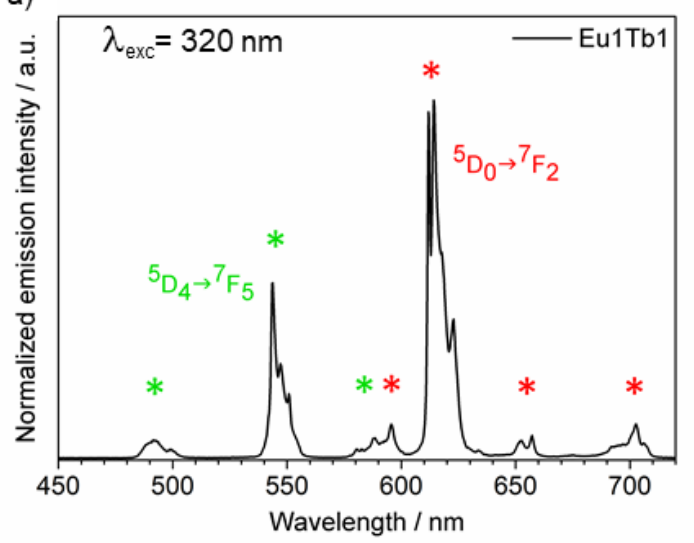

c) Eu1Tb1

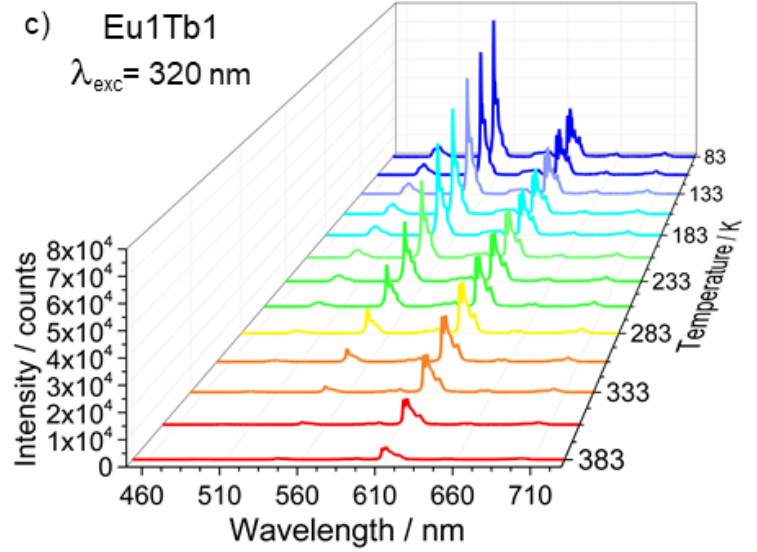

b)

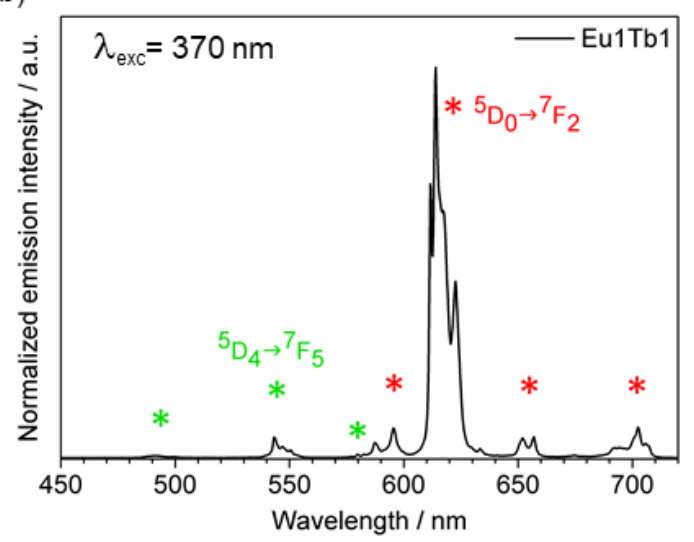

d) Eu1Tb1

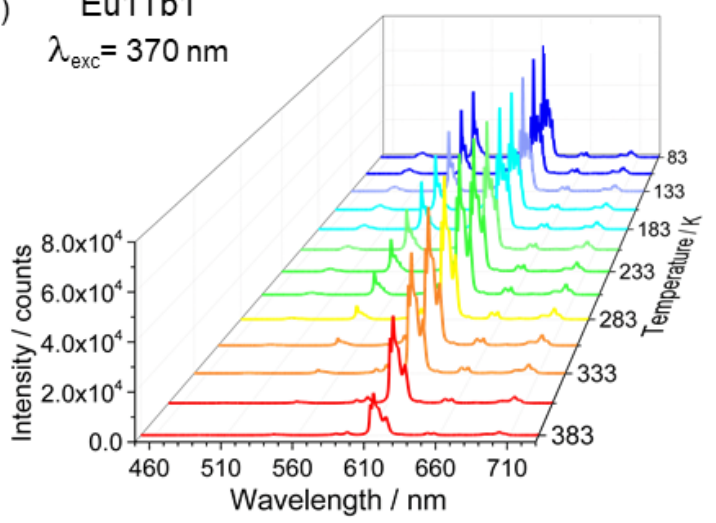

Figure 7. (a,b) Room temperature and (c,d) temperature-dependent emission spectra of sample Eu1Tb1. $(\mathbf{a}-\mathbf{c}) \lambda_{\operatorname{exc}}=320 \mathrm{~nm}$, $(\mathbf{b}-\mathbf{d}) \lambda_{\text {exc }}=370 \mathrm{~nm}$. In $(\mathbf{a}, \mathbf{b}) \mathrm{Tb}^{3+}$ emissions are labelled with green asterisks, while $\mathrm{Eu}^{3+}$ transitions with red ones. 
Temperature $/{ }^{\circ} \mathrm{C}$
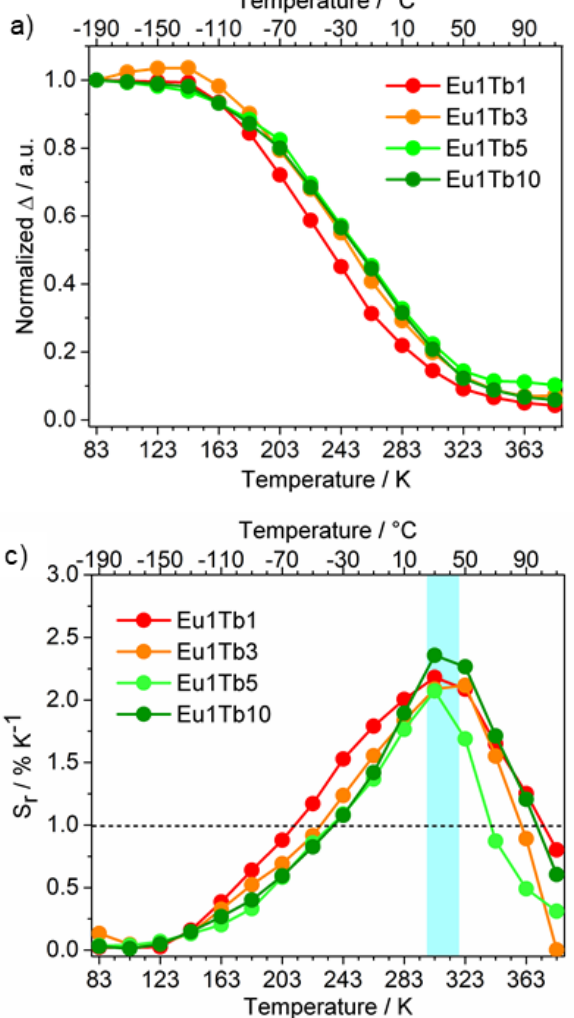

Temperature $/{ }^{\circ} \mathrm{C}$

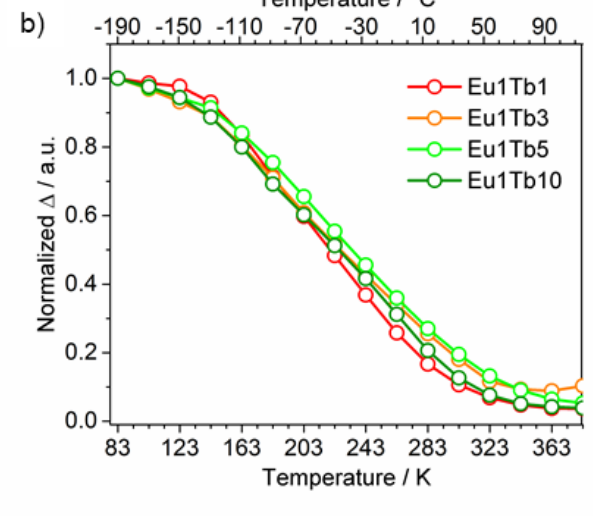

Temperature $/{ }^{\circ} \mathrm{C}$
d) $\quad 30,-190,-110,-70,-30,10,50,90$

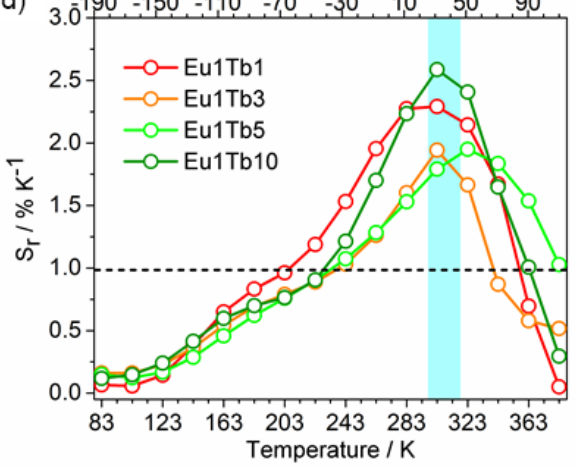

Figure 8. (a,b) Normalized $\Delta$ vs. T and (c,d) $S_{r}$ curves of Eu-Tb mixed samples; in light blue is reported the physiological temperature range. $(\mathbf{a}-\mathbf{c}) \lambda_{\mathrm{exc}}=320 \mathrm{~nm},(\mathbf{b}-\mathbf{d}) \lambda_{\mathrm{exc}}=370 \mathrm{~nm}$.
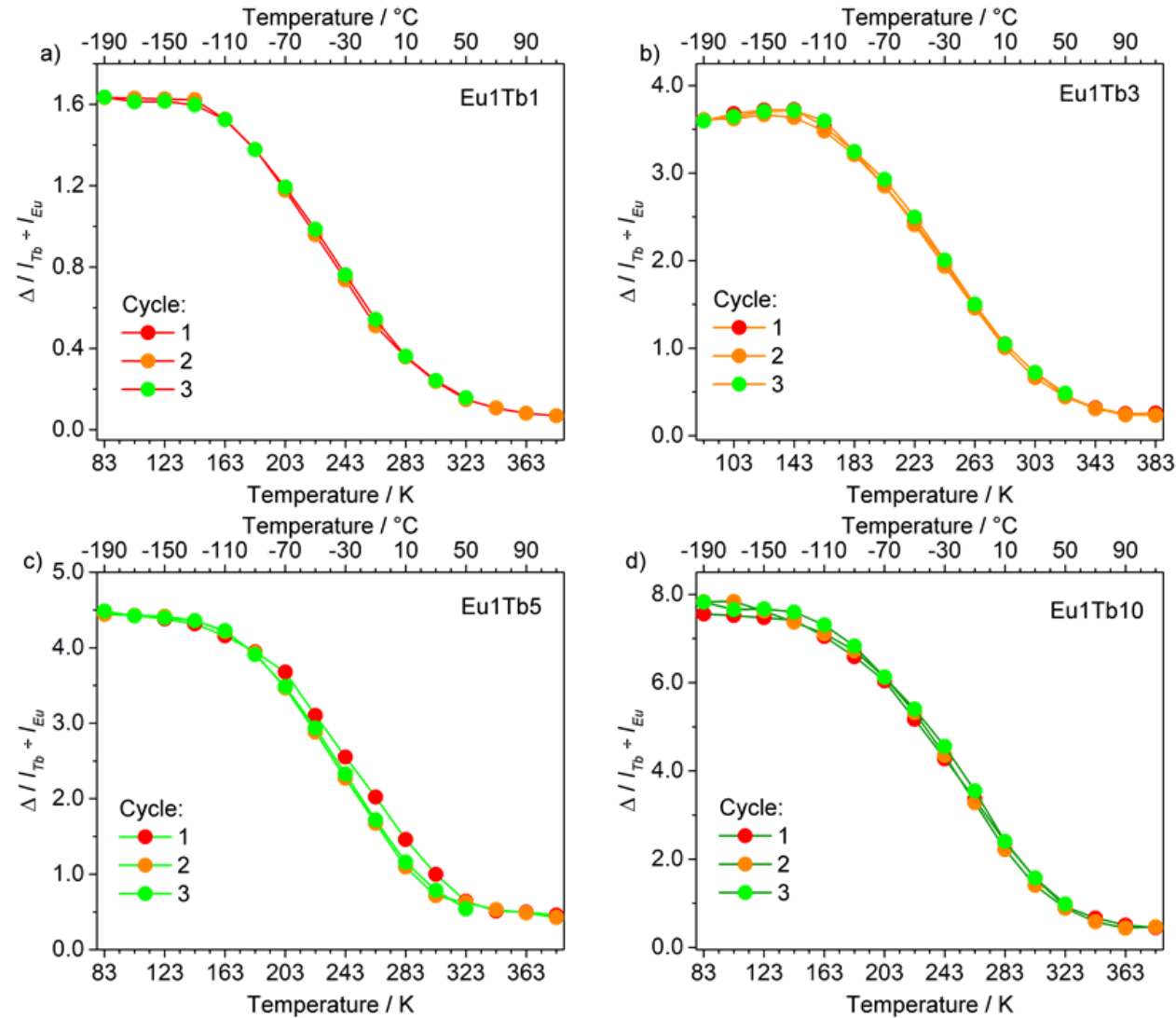

Figure 9. Heating/freezing cycles for samples (a) Eu1Tb1, (b) Eu1Tb3, (c) Eu1Tb5, and (d) Eu1Tb10. $\lambda_{\text {exc }}=320 \mathrm{~nm}$. 
The temperature resolution of our thermometers, i.e., the smallest detectable temperature variation $(\delta \mathrm{T})$, was determined by the heating/freezing cycles, according to literature $[2,3,18]$, using the following equation:

$$
\delta \mathrm{T}=\frac{1}{\mathrm{~S}_{\mathrm{r}}} \cdot \frac{\delta \Delta}{\Delta}
$$

where $\delta \Delta$ is the $\Delta$ uncertainty at a given temperature $[3,6]$ determined by calculating the standard deviation of three heating/freezing cycles. All the samples showed comparable resolution in the order of $0.01 \mathrm{~K}$ (average value over the thermometer operational range), in line with literature values for Ln-based luminescence thermometers $[2,3]$.

The change of the excitation wavelength produces a variation of the samples color outputs. Indeed, at $370 \mathrm{~nm}$, the green component due to terbium emission is less intense than at $320 \mathrm{~nm}$, thus producing an overall chromatic shift towards red (Figure 10).

a)

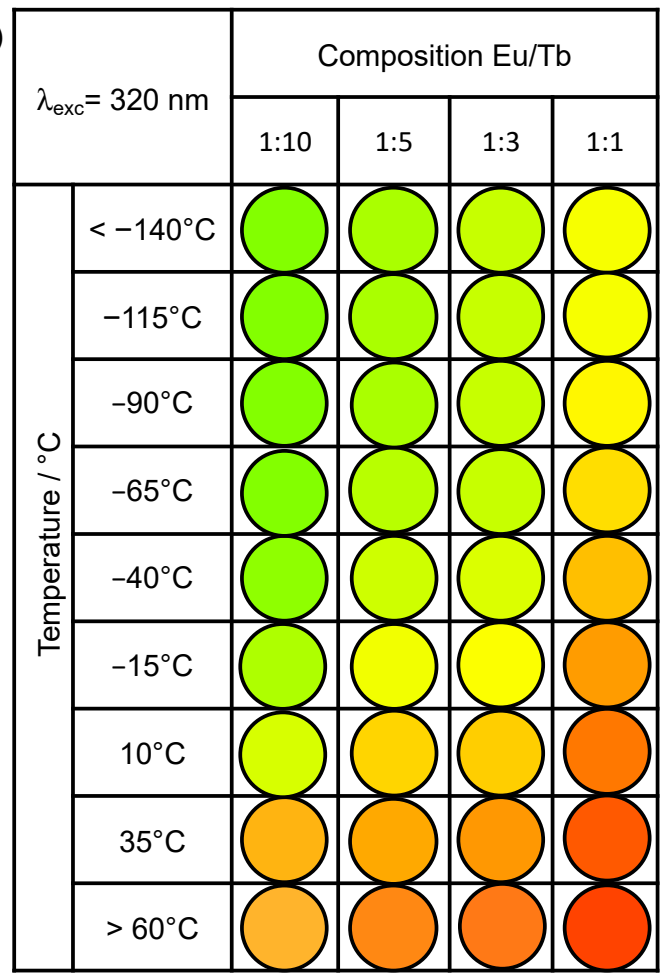

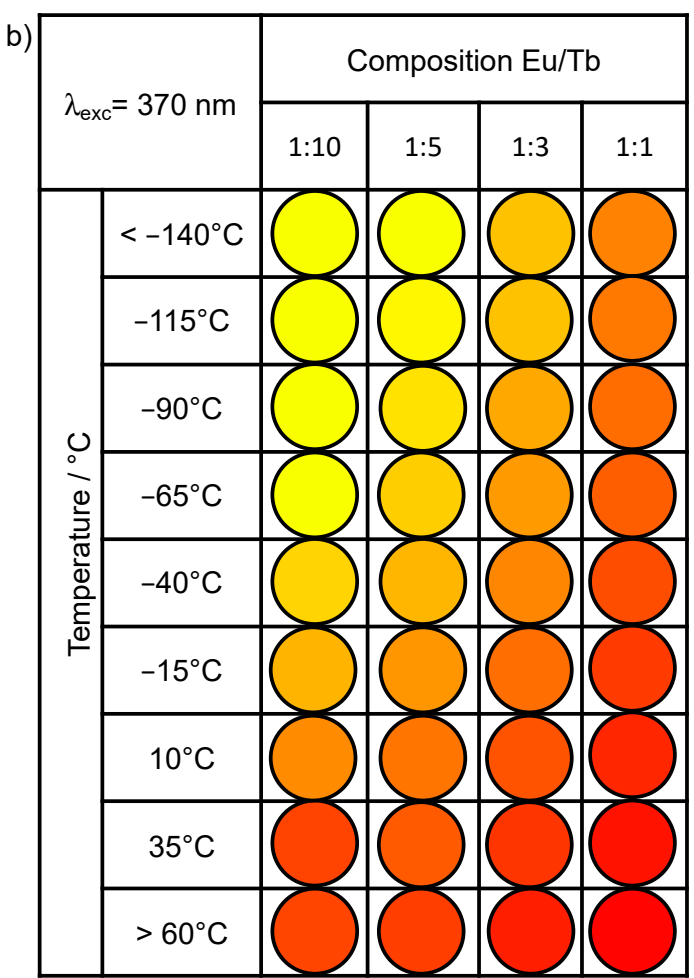

Figure 10. Overall chromatic variation for the studied samples excited at (a) $320 \mathrm{~nm}$ and (b) $370 \mathrm{~nm}$.

Figure 10 shows a schematic diagram representing the color variation of the different samples over the 83-383 K temperature range. The color at the different temperatures is defined by the CIE coordinates determined from the emission spectra obtained exciting the samples at 320 and $370 \mathrm{~nm}$. Note how the temperature can be mapped by a chromatic reading generating something similar to the litmus paper, the famous $\mathrm{pH}$ testing papers, that can work with one or more chromatic channels simply defined by the composition of the mixture of $\mathbf{1}$ and 2. Noteworthy, the correlation between the color of the emitted light and sample composition can also be used for the development of luminescent QRcodes [24] in which the temperature can be associated to a single color or a combination of two or more tints. In principle, the tuning of the europium/terbium relative amount should enable the optimization of the color gradient, thus allowing the detection of even narrower temperature intervals. 


\section{Conclusions}

In this work, the temperature-dependent luminescent properties of the two homometallic 1D zigzag $\left[\mathrm{Ln}(\mathrm{hfac})_{3} \text { bipy }\right]_{\mathrm{n}} \mathrm{CPs}\left(\mathrm{Ln}^{3+}=\mathrm{Eu}^{3+}, 1\right.$, and $\left.\mathrm{Tb}^{3+}, 2\right)$ were studied in the 83-383 K temperature range. 1 and 2 showed $S_{r}$ values higher than 1 starting from $323 \mathrm{~K}$ and $223 \mathrm{~K}$, respectively. The two homometallic compounds were then used to prepare a family of $\mathrm{Eu}^{3+} / \mathrm{Tb}^{3+}$ ratiometric thermometers in which terbium acts as probe and europium as reference. Four different thermometers were prepared by mixing different amounts of $\mathbf{1}$ and $\mathbf{2}$ in $\mathrm{KBr}$ matrix with $\mathrm{Eu}^{3+} / \mathrm{Tb}^{3+}$ molar ratio of 1:1, 1:3, 1:5, and 1:10, respectively. Sample composition and the excitation wavelength influenced the color of the emitted light but not the thermometric response. All the thermometers were sensitive to temperature variation between $83-383 \mathrm{~K}$, showing a wide applicative range $\left(\mathrm{S}_{\mathrm{r}} \geq 1\right)$ from $100 \mathrm{~K}$ to $165 \mathrm{~K}$ depending on the sample composition. The samples showed high relative thermal sensitivity values in the physiological temperature range (298-318 K), with a $\mathrm{S}_{\mathrm{r}}$ maximum value of about $2.40 \% \mathrm{~K}^{-1}$. The thermometric response of the samples did not vary significantly in changing the excitation wavelength that, instead, influences the color of the emitted light. The well-defined and peculiar color variation of heterobimetallic materials is used as a colorimetric thermometer. Using the eyes as a detector, temperature difference in the order of $10-20 \mathrm{~K}$ can be appreciated. To improve the temperature resolution, using the color of the emitted light as probe, calibrated luminance/color meters are required. The results here reported pose the basis for future activity oriented to bring luminescent molecular thermometer into daily life by measuring temperature by reading the color of the emitted light with a smartphone camera.

Supplementary Materials: The following are available online at https:/ / www.mdpi.com/article/1 $0.3390 / \mathrm{ma14216445/s1}$, Figure S1: Superimposed infrared spectra of $\left[\mathrm{Eu}(\mathrm{hfac})_{3}(\mathrm{bipy})\right]_{\mathrm{n}}(\mathbf{1}$, red $)$ and $\left[\mathrm{Tb}(\mathrm{hfac})_{3} \text { (bipy) }\right]_{\mathrm{n}}\left(2\right.$, green) CPs in the $2000-650 \mathrm{~cm}^{-1}$ wavenumber range; Figure S2: Excitation spectra of compound 1 (red) and 2 (green), $\lambda_{\mathrm{em}}=614$ and $543 \mathrm{~nm}$, respectively. The vertical dashed lines highlight the two excitation wavelengths used in the work (320 and $370 \mathrm{~nm}$ ); Figure S3: Room temperature emission spectra of samples (a) Eu1Tb3, (b) Eu1Tb5 and (c) Eu1Tb10. $\lambda_{\text {exc }}=$ 320 nm; Figure S4: Room temperature emission spectra of samples (a) Eu1Tb3, (b) Eu1Tb5 and (c) Eu1Tb10. $\lambda_{\mathrm{exc}}=370 \mathrm{~nm}$; Figure S5: Temperature-dependent emission spectra of samples (a) Eu1Tb3, (b) Eu1Tb5 and (c) Eu1Tb10. $\lambda_{\text {exc }}=320$ nm; Figure S6: Temperature-dependent emission spectra of samples (a) Eu1Tb3, (b) Eu1Tb5 and (c) Eu1Tb10. $\lambda_{\text {exc }}=370$ nm; Figure S7: $\Delta$ vs. T curves of Eu-Tb mixed samples. (a) $\lambda_{\mathrm{exc}}=320 \mathrm{~nm}$, (b) $\lambda_{\mathrm{exc}}=370 \mathrm{~nm}$.

Author Contributions: Conceptualization, L.B., G.B., L.L. and L.A.; methodology, L.B. and G.B.; investigation, L.B., G.B., S.S. and F.M.; data curation, L.B. and G.B.; writing-original draft preparation, L.B. and G.B.; writing-review and editing, L.B. and G.B.; supervision, G.B., D.B.D., L.L. and L.A. All authors have read and agreed to the published version of the manuscript.

Funding: This research received no external funding.

Institutional Review Board Statement: Not applicable.

Informed Consent Statement: Not applicable.

Data Availability Statement: Not applicable.

Conflicts of Interest: The authors declare no conflict of interest.

\section{References}

1. Uchiyama, S.; Gota, C.; Tsuji, T.; Inada, N. Intracellular temperature measurements with fluorescent polymeric thermometers. Chem. Commun. 2017, 53, 10976-10992. [CrossRef]

2. Brites, C.D.S.; Millán, A.; Carlos, L.D. Lanthanides in Luminescent Thermometry. In Handbook on the Physics and Chemistry of Rare Earths; Elsevier B.V.: Amsterdam, The Netherlands, 2016; Volume 49, pp. 339-427.

3. Brites, C.D.S.; Balabhadra, S.; Carlos, L.D. Lanthanide-Based Thermometers: At the Cutting-Edge of Luminescence Thermometry. Adv. Opt. Mater. 2019, 7, 1801239. [CrossRef]

4. Liu, T.; Campbell, B.T.; Burns, S.P.; Sullivan, J.P. Temperature- and Pressure-Sensitive Luminescent Paints in Aerodynamics. Appl. Mech. Rev. 2009, 50, 227-246. [CrossRef] 
5. Liu, T. Pressure- and Temperature-Sensitive Paints. In Encyclopedia of Aerospace Engineering; John Wiley \& Sons, Ltd.: Hoboken, NJ, USA, 2011.

6. Carlos, L.D.; Palacio, F.; Quintanilla, M.; Benayas, A.; Naccache, R.; Vetrone, F.; Carlos, L.D.; Palacio, F. Thermometry at the Nanoscale: Techniques and Selected Applications; The Royal Society of Chemistry: London, UK, 2016.

7. Dramićanin, M. Luminescence Thermometry; Elsevier: Amsterdam, The Netherlands, 2018.

8. Brites, C.D.S.; Lima, P.P.; Silva, N.J.O.; Millán, A.; Amaral, V.S.; Palacio, F.; Carlos, L.D. Thermometry at the nanoscale. Nanoscale 2012, 4, 4799-4829. [CrossRef] [PubMed]

9. Brites, C.D.S.; Lima, P.P.; Carlos, L.D. Tuning the sensitivity of $\mathrm{Ln}^{3+}$-based luminescent molecular thermometers through ligand design. J. Lumin. 2016, 169, 497-502. [CrossRef]

10. Ross, D.; Gaitan, M.; Locascio, L.E. Temperature Measurement in Microfluidic Systems Using a Temperature-Dependent Fluorescent Dye. Anal. Chem. 2001, 73, 4117-4123. [CrossRef]

11. Rocha, J.; Brites, C.D.S.; Carlos, L.D. Lanthanide Organic Framework Luminescent Thermometers. Chem. Eur. J. 2016, 22, 14782-14795. [CrossRef]

12. Peng, H.; Stich, M.I.J.; Yu, J.; Sun, L.; Fischer, L.H.; Wolfbeis, O.S. Luminescent Europium(III) Nanoparticles for Sensing and Imaging of Temperature in the Physiological Range. Adv. Mater. 2010, 22, 716-719. [CrossRef] [PubMed]

13. Brites, C.D.S.; Lima, P.P.; Silva, N.J.O.; Millán, A.; Amaral, V.S.; Palacio, F.; Carlos, L.D. A luminescent molecular thermometer for long-term absolute temperature measurements at the nanoscale. Adv. Mater. 2010, 22, 4499-4504. [CrossRef]

14. Cadiau, A.; Brites, C.D.S.; Costa, P.M.F.J.; Ferreira, R.A.S.; Rocha, J.; Carlos, L.D. Ratiometric Nanothermometer Based on an Emissive Ln $^{3+}$-Organic Framework. ACS Nano 2013, 7, 7213-7218. [CrossRef]

15. Wang, Z.; Ananias, D.; Carné-Sánchez, A.; Brites, C.D.S.; Imaz, I.; Maspoch, D.; Rocha, J.; Carlos, L.D. Lanthanide-Organic Framework Nanothermometers Prepared by Spray-Drying. Adv. Funct. Mater. 2015, 25, 2824-2830. [CrossRef]

16. Brites, C.D.S.; Lima, P.P.; Silva, N.J.O.; Millán, A.; Amaral, V.S.; Palacio, F.; Carlos, L.D. Lanthanide-based luminescent molecular thermometers. New J. Chem. 2011, 35, 1177. [CrossRef]

17. Cui, Y.; Zhu, F.; Chen, B.; Qian, G. Metal-organic frameworks for luminescence thermometry. Chem. Commun. 2015, 51, 7420-7431. [CrossRef]

18. De Bellis, J.; Bellucci, L.; Bottaro, G.; Labella, L.; Marchetti, F.; Samaritani, S.; Belli Dell'Amico, D.; Armelao, L. Single-crystal-tosingle-crystal post-synthetic modifications of three-dimensional $\mathrm{LOFs}(\mathrm{Ln}=\mathrm{Gd}, \mathrm{Eu})$ : A way to modulate their luminescence and thermometric properties. Dalt. Trans. 2020, 49, 6030-6042. [CrossRef]

19. Osborn Popp, T.M.; Yaghi, O.M. Sequence-Dependent Materials. Acc. Chem. Res. 2017, 50, 532-534. [CrossRef]

20. Bellucci, L.; Bottaro, G.; Labella, L.; Marchetti, F.; Samaritani, S.; Belli Dell'Amico, D.; Armelao, L. Luminescent sequencedependent materials through a step by step assembly of $\mathrm{RE}^{1}-1,4$-benzendicarboxylate- $\mathrm{RE}^{2}\left(\mathrm{RE}^{\mathrm{x}}=\mathrm{Y}^{3+}, \mathrm{Eu}^{3+}\right.$ and $\left.\mathrm{Tb}^{3+}\right)$ architectures on a silica surface. J. Mater. Chem. C 2019, 7, 4415-4423. [CrossRef]

21. Zhou, H.C.J.; Kitagawa, S. Metal-Organic Frameworks (MOFs). Chem. Soc. Rev. 2014, 43, 5415-5418. [CrossRef]

22. Farrusseng, D. Metal-Organic Frameworks: Applications from Catalysis to Gas Storage; Wiley: Hoboken, NJ, USA, 2011.

23. Rao, X.; Song, T.; Gao, J.; Cui, Y.; Yang, Y.; Wu, C.; Chen, B.; Qian, G. A Highly Sensitive Mixed Lanthanide Metal-Organic Framework Self-Calibrated Luminescent Thermometer. J. Am. Chem. Soc. 2013, 135, 15559-15564. [CrossRef]

24. Ramalho, J.F.C.B.; Correia, S.F.H.; Fu, L.; António, L.L.F.; Brites, C.D.S.; André, P.S.; Ferreira, R.A.S.; Carlos, L.D. Luminescence Thermometry on the Route of the Mobile-Based Internet of Things (IoT): How Smart QR Codes Make It Real. Adv. Sci. 2019, 6, 1900950. [CrossRef] [PubMed]

25. Liu, X.; Akerboom, S.; De Jong, M.; Mutikainen, I.; Tanase, S.; Meijerink, A.; Bouwman, E. Mixed-Lanthanoid Metal-Organic Framework for Ratiometric Cryogenic Temperature Sensing. Inorg. Chem. 2015, 54, 11323-11329. [CrossRef] [PubMed]

26. Cui, Y.; Zou, W.; Song, R.; Yu, J.; Zhang, W.; Yang, Y.; Qian, G. A ratiometric and colorimetric luminescent thermometer over a wide temperature range based on a lanthanide coordination polymer. Chem. Commun. 2014, 50, 719-721. [CrossRef]

27. Miyata, K.; Konno, Y.; Nakanishi, T.; Kobayashi, A.; Kato, M.; Fushimi, K.; Hasegawa, Y. Chameleon luminophore for sensing temperatures: Control of metal-to-metal and energy back transfer in lanthanide coordination polymers. Angew. Chemie Int. Ed. 2013, 52, 6413-6416. [CrossRef] [PubMed]

28. Hatanaka, M.; Hirai, Y.; Kitagawa, Y.; Nakanishi, T.; Hasegawa, Y.; Morokuma, K. Organic linkers control the thermosensitivity of the emission intensities from $\mathrm{Tb}(\mathrm{III})$ and $\mathrm{Eu}(\mathrm{III})$ in a chameleon polymer. Chem. Sci. 2016, 8, 423-429. [CrossRef]

29. Bellucci, L.; Bottaro, G.; Labella, L.; Causin, V.; Marchetti, F.; Samaritani, S.; Belli Dell'Amico, D.; Armelao, L. CompositionThermometric properties correlations in homodinuclear $\mathrm{Eu}^{3+}$ luminescent complexes. Inorg. Chem. 2020, 59, 18156-18167. [CrossRef]

30. Swavey, S.; Krause, J.A.; Collins, D.; D'Cunha, D.; Fratini, A. X-ray structure and temperature dependent luminescent properties of two bimetallic europium complexes. Polyhedron 2008, 27, 1061-1069. [CrossRef]

31. Sato, S.; Wada, M. Relations between Intramolecular Energy Transfer Efficiencies and Triplet State Energies in Rare Earth ß-diketone Chelates. Bull. Chem. Soc. Jpn. 1970, 43, 1955-1962. [CrossRef]

32. Carlotto, A.; Babetto, L.; Carlotto, S.; Miozzi, M.; Seraglia, R.; Casarin, M.; Bottaro, G.; Rancan, M.; Armelao, L. Luminescent Thermometers: From a Library of Europium(III) $\beta$-Diketonates to a General Model for Predicting the Thermometric Behaviour of Europium-Based Coordination Systems. ChemPhotoChem 2020, 4, 644. [CrossRef] 
33. Armelao, L.; Belli Dell'Amico, D.; Bellucci, L.; Bottaro, G.; Labella, L.; Marchetti, F.; Samaritani, S. A convenient synthesis of highly luminescent lanthanide 1D-zigzag coordination chains based only on 4,4'-bipyridine as connector. Polyhedron 2016, 119, 371-376. [CrossRef]

34. Bellucci, L.; Labella, L.; Marchetti, F.; Pineider, F.; Poneti, G.; Samaritani, S. Magnetic relaxation in dysprosium and terbium 1D-zigzag coordination chains having only 4,4'-bipyridine as connector. Inorg. Chim. Acta 2021, 516, 120165. [CrossRef]

35. Biradha, K.; Sarkar, M.; Rajput, L. Crystal engineering of coordination polymers using $4,4^{\prime}$-bipyridine as a bond between transition metal atoms. Chem. Commun. 2006, 4169-4179. [CrossRef]

36. Quici, S.; Scalera, C.; Cavazzini, M.; Accorsi, G.; Bolognesi, M.; Armelao, L.; Bottaro, G. Highly photoluminescent silica layers doped with efficient $\mathrm{Eu}(\mathrm{III})$ and $\mathrm{Tb}(\mathrm{III})$ antenna complexes. Chem. Mater. 2009, 21, 2941-2949. [CrossRef]

37. Eliseeva, S.V.; Pleshkov, D.N.; Lyssenko, K.A.; Lepnev, L.S.; Bünzli, J.C.G.; Kuzmina, N.P. Highly luminescent and triboluminescent coordination polymers assembled from lanthanide $\beta$-diketonates and aromatic bidentate O-donor ligands. Inorg. Chem. 2010, 49, 9300-9311. [CrossRef] [PubMed]

38. Binnemans, K. Interpretation of europium(III) spectra. Coord. Chem. Rev. 2015, 295, 1-45. [CrossRef]

39. Gónzalez-Fabra, J.; Bandeira, N.A.G.; Velasco, V.; Barrios, L.A.; Aguilà, D.; Teat, S.J.; Roubeau, O.; Bo, C.; Aromí, G. Thermodynamic Stability of Heterodimetallic [LnLn'] Complexes: Synthesis and DFT Studies. Chem. Eur. J. 2017, 23, 5117-5125. [CrossRef]

40. André, N.; Jensen, T.B.; Scopelliti, R.; Imbert, D.; Elhabiri, M.; Hopfgartner, G.; Piguet, C.; Bünzli, J.C.G. Supramolecular Recognition of Heteropairs of Lanthanide Ions: A Step toward Self-Assembled Bifunctional Probes. Inorg. Chem. 2004, 43, 515-529. [CrossRef] [PubMed]

41. Armelao, L.; Belli Dell'Amico, D.; Bellucci, L.; Bottaro, G.; Ciattini, S.; Labella, L.; Manfroni, G.; Marchetti, F.; Mattei, C.A.; Samaritani, S. Homodinuclear Lanthanide Complexes with the Divergent Heterotopic 4,4'-Bipyridine N-Oxide (bipyMO) Ligand. Eur. J. Inorg. Chem. 2018, 2018, 4421-4428. [CrossRef]

42. Seward, C.; Wang, S. Dimeric and polymeric $\left[\mathrm{Eu}(\mathrm{tta})_{3} \mathrm{~L}\right]$ complexes (tta $=$ thenoyltrifluoroacetonato, $\mathrm{L}=4,4^{\prime}$-bipyridine, trans-1,2bis(4-pyridyl)ethylene, 4,4'-bipyridine- $N, N^{\prime}$-dioxide). Can. J. Chem. 2001, 79, 1187-1193. [CrossRef]

43. Lima, P.P.; Paz, F.A.A.; Brites, C.D.S.; Quirino, W.G.; Legnani, C.; Costa E Silva, M.; Ferreira, R.A.S.; Júnior, S.A.; Malta, O.L.; Cremona, M.; et al. White OLED based on a temperature sensitive $\mathrm{Eu}^{3+} / \mathrm{Tb}^{3+} \beta$-diketonate complex. Org. Electron. 2014, 15, 798-808. [CrossRef]

44. Bünzli, J.-C.G. On the design of highly luminescent lanthanide complexes. Coord. Chem. Rev. 2015, 293, 19-47. [CrossRef]

45. Armelao, L.; Belli Dell'Amico, D.; Biagini, P.; Bottaro, G.; Chiaberge, S.; Falvo, P.; Labella, L.; Marchetti, F.; Samaritani, S. Preparation of N,N-Dialkylcarbamato Lanthanide Complexes by Extraction of Lanthanide Ions from Aqueous Solution into Hydrocarbons. Inorg. Chem. 2014, 53, 4861-4871. [CrossRef]

46. Binnemans, K. Rare-Earth Beta-Diketonates. In Handbook on the Physics and Chemistry of Rare Earths; Elsevier B.V.: Amsterdam, The Netherlands, 2005; Volume 225, pp. 111-277.

47. Miyata, K.; Ohba, T.; Kobayashi, A.; Kato, M.; Nakanishi, T.; Fushimi, K.; Hasegawa, Y. Thermostable Organo-phosphor: Low-Vibrational Coordination Polymers That Exhibit Different Intermolecular Interactions. Chempluschem 2012, 77, $277-280$. [CrossRef] 